\title{
OPEN Pol $\mu$ ribonucleotide insertion opposite 8-oxodG facilitates the ligation of premutagenic DNA repair intermediate
}

\author{
Melike Çağlayan \\ DNA polymerase (pol) $\mu$ primarily inserts ribonucleotides into a single-nucleotide gapped DNA \\ intermediate, and the ligation step plays a critical role in the joining of noncomplementary DNA ends \\ during nonhomologous end joining (NHEJ) for the repair of double-strand breaks (DSBs) caused by \\ reactive oxygen species. Here, we report that the pol $\mu$ insertion products of ribonucleotides (rATP or \\ rCTP), instead of deoxyribonucleotides, opposite 8-oxo-2'-deoxyguanosine (8-oxodG) are efficiently \\ ligated and the presence of $\mathrm{Mn}^{2+}$ stimulates this coupled reaction in vitro. Moreover, our results point \\ to a role of pol $\mu$ in mediating ligation during the mutagenic bypass of 8-oxodG, while 3'-preinserted \\ noncanonical base pairs $\left(3^{\prime}-\mathrm{rA}\right.$ or $\left.3^{\prime}-\mathrm{rC}\right)$ on NHEJ repair intermediates compromise the end joining by \\ DNA ligase I or the DNA ligase IV/XRCC4 complex.
}

The concentration of ribonucleoside triphosphates (rNTPs) in the intracellular nucleotide pool is higher than that of deoxyribonucleotides (dNTPs), and the insertion of ribonucleotides into genomic DNA can hinder replication and transcription ${ }^{1-4}$. DNA polymerase (pol) $\mu$, which lacks proofreading activity, inserts both dNTPs and rNTPs in a template-dependent manner during nonhomologous end joining (NHEJ) in the repair of double-strand breaks (DSBs) that are generated by ionizing radiation or reactive oxygen species as well as endogenous DNA metabolic processes ${ }^{5-9}$. Pol $\mu$ displays the lowest discrimination for the sugar moiety of the nucleic acid strand and shows a normal active site geometry lacking a 'steric gate' amino acid side chain compared to those of other X family DNA polymerases with greater discrimination, such as pol $\beta^{10-14}$. Pol $\mu$ contributes to the general error-prone bypass of certain types of DNA lesions, such as 8-oxo-2'-deoxyguanosine (8-oxodG) $)^{15-19}$. Very recently, the precatalytic ternary complex structure of the pol $\mu$ active site in lesion bypass of a template 8-oxodG has been shown ${ }^{20}$. Almost all DNA polymerases prefer magnesium $\left(\mathrm{Mg}^{2+}\right)$ over the other divalent metal ions for catalysis, and manganese $\left(\mathrm{Mn}^{2+}\right)$ is considered to be a metal mutagen ${ }^{21-24}$. It has been shown that pol $\mu$ is activated at physiological $\mathrm{Mn}^{2+}$ concentrations in vitro, and the unusual $\mathrm{Mn}^{2+}$ preference of pol $\mu$ improves the efficiency of NHEJ with increased ribonucleotide insertion rate ${ }^{25}$. Recently, the noncanonical mechanism of ribonucleotide insertion into a single-nucleotide gapped NHEJ repair intermediate by pol $\mu$ favoring $\mathrm{Mn}^{2+}$ over $\mathrm{Mg}^{2+}$ has been reported ${ }^{26}$.

As the favored pathway for DSB repair, classical NHEJ involves protein-protein interactions between several components of the repair machinery ${ }^{27-29}$. In this process, the recognition and processing of broken DNA ends require the Ku 70/80 heterodimer in conjunction with the DNA-dependent protein kinase catalytic subunit, the DNA ligase IV/X-ray cross complementing protein 4 (XRCC4) complex, and Artemis ${ }^{30}$. During this process, pol $\mu$, which fills gaps by nucleotide insertion, is known to play an important role in resolving DSBs ${ }^{31,32}$. The impact of the ligation step on NHEJ fidelity and the significance of DNA ligase IV in sensing diverse strand breaks after ionizing radiation have also been reported ${ }^{33,34}$. Our previous work revealed that pol $\mu$ Watson-Crick-like $\mathrm{dG}: \mathrm{dT}$ insertion facilitates the ligation of strand break repair intermediates, suggesting the accommodation of the coupled reaction by pol $\mu$ and DNA ligase during $\mathrm{NHEJ}^{35}$, similar to the well-known substrate channeling mechanism in which DNA repair intermediates are transferred in a highly coordinated manner during the base excision repair (BER) pathway ${ }^{36,37}$. Recently, it has been proposed in a triple strand break reaction model that the ribonucleotides primarily inserted by pol $\mu$ promote ligation during the repair of chromosome breaks in vivo ${ }^{38}$. 

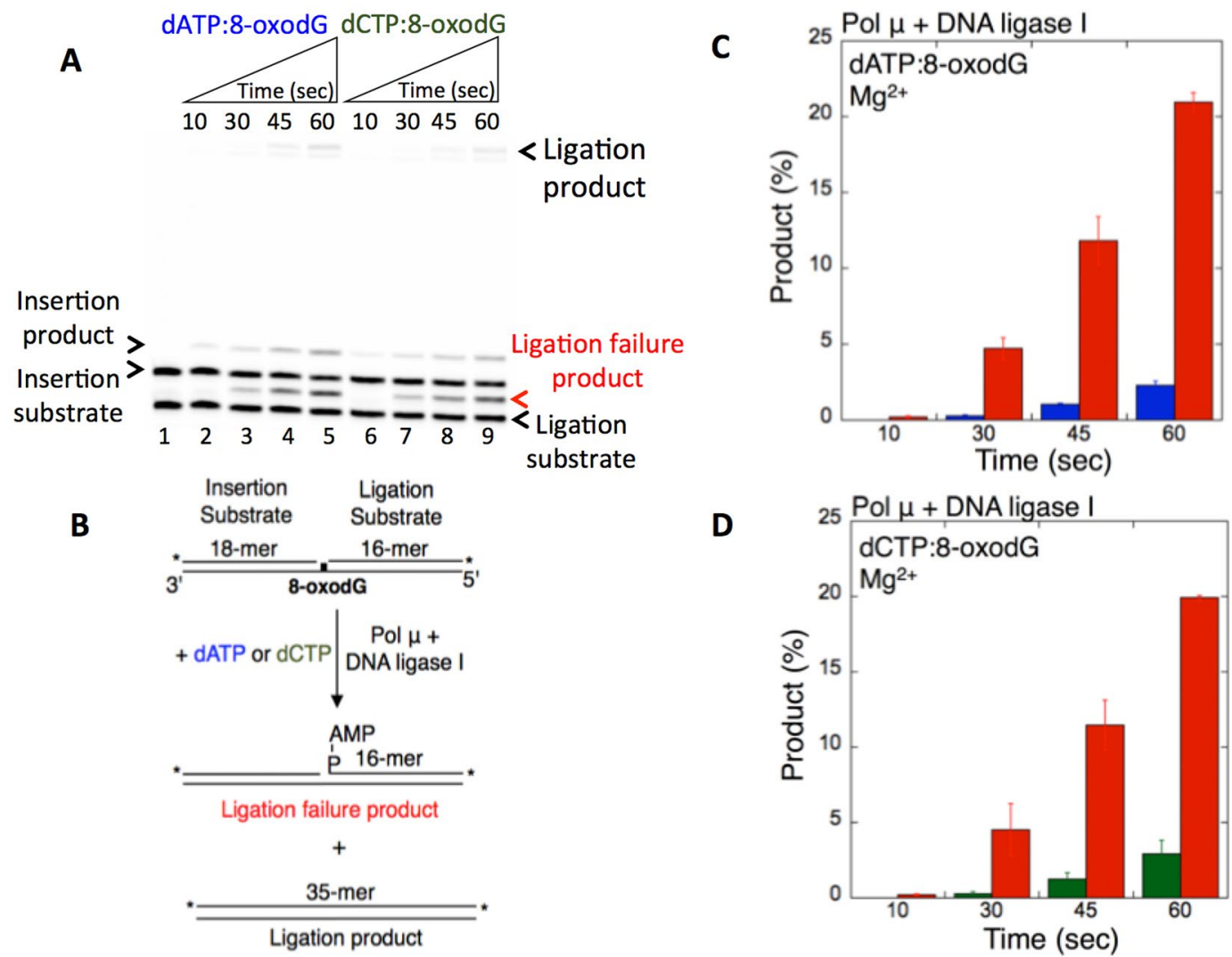

D

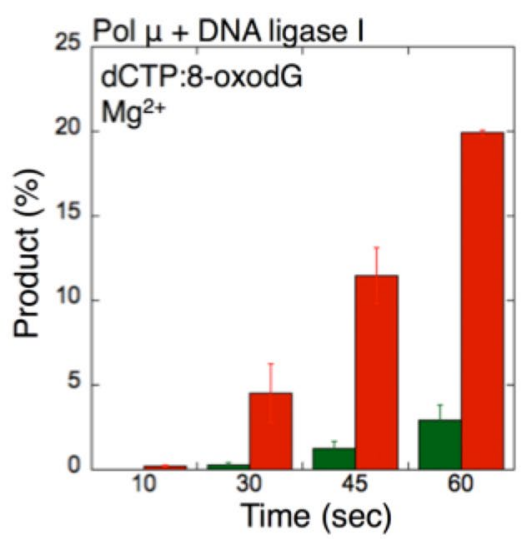

Figure 1. Pol $\mu \mathrm{dATP}$ and dCTP insertion opposite 8-oxodG coupled with ligation by DNA ligase I in the presence of $\mathrm{Mg}^{2+}$. (A) Lane 1 is the minus enzyme control for the one nucleotide gapped DNA substrate with template 8-oxodG. Lanes 2-5 and 6-9 are the coupled reaction products in the presence of dATP or $\mathrm{dCTP}$, respectively, and correspond to time points of 10,30,45, and $60 \mathrm{sec}$. The scheme illustrates the DNA substrates and reaction products observed in the coupled assay. (B,C) Graphs show time-dependent changes in the products of ligation (blue and green) and ligation failure (red). The data represent the average of three independent experiments \pm SD. Corresponding uncropped gel image is shown in Supplementary Fig. 15.

In this study, we investigated the impact of pol $\mu$ ribonucleotide vs deoxyribonucleotide insertion into a model DSB repair substrate with a single-nucleotide gap as well as the effect of the metal ion $\left(\mathrm{Mg}^{2+} \mathrm{vs} \mathrm{Mn}^{2+}\right)$ on ligation by DNA ligase I or the DNA ligase IV/XRCC4 complex. We showed that the pol $\mu$ ribonucleotide insertion products of rATP and rCTP opposite 8-oxodG or dG are efficiently ligated, and the presence of $\mathrm{Mn}^{2+}$ stimulates this coupled reaction in vitro. Moreover, the ligation of the nicked substrate with preinserted ribonucleotides $\left(3^{\prime}-\mathrm{rA}\right.$ or $3^{\prime}$-rC opposite 8-oxodG or dG) is compromised by subtle changes in the structure of the DNA ends. Overall, the results indicate a significant role of ribonucleotide insertion and the requirement of pol $\mu$ for efficient ligation of the NHEJ repair intermediate during the coupled double-strand break repair.

\section{Results}

Ligation of pol $\mu$ deoxyribonucleotide vs ribonucleotide insertion products during mutagenic bypass of template 8-oxodG. To understand the ligation of the repair intermediates by DNA ligase after pol $\mu$-mediated deoxyribonucleotide vs ribonucleotide insertion, we first measured dNTP (dATP or dCTP) vs rNTP (rATP or rCTP) insertion coupled with ligation in a reaction mixture containing pol $\mu$ and DNA ligase I or the DNA ligase IV/XRCC4 complex (Supplementary Scheme 1). For this purpose, we used the model end joining DNA substrate with a single-nucleotide gap and a template 8-oxodG (Supplementary Table 1).

We observed that pol $\mu \mathrm{dATP}$ or dCTP insertion opposite 8-oxodG confounds the ligation and results in ligation failure (Fig. 1A, lanes 2-5 and 6-9), as revealed by the time-dependent (10-60 sec) change in the formation of the $5^{\prime}$-adenylate product, i.e., AMP addition to the $5^{\prime}$-end of the substrate (Fig. 1C,D) obtained in a coupled BER assay (Fig. 1B). For longer time points $(0.5-10 \mathrm{~min})$, we obtained both ligation and a stable amount of ligation failure products after pol $\mu \mathrm{dATP}$ and dCTP insertions opposite 8-oxodG in a coupled reaction including DNA ligase I or the DNA ligase IV/XRCC4 complex (Supplementary Fig. 1). On the other hand, the repair intermediate with a $3^{\prime}$-ribonucleotide inserted by pol $\mu$ bypassing 8 -oxodG is efficiently ligated. In this case, pol $\mu$ rATP and rCTP insertions opposite 8-oxodG enabled ligation (Fig. 2A), and only ligation products were observed (Fig. 2B). 

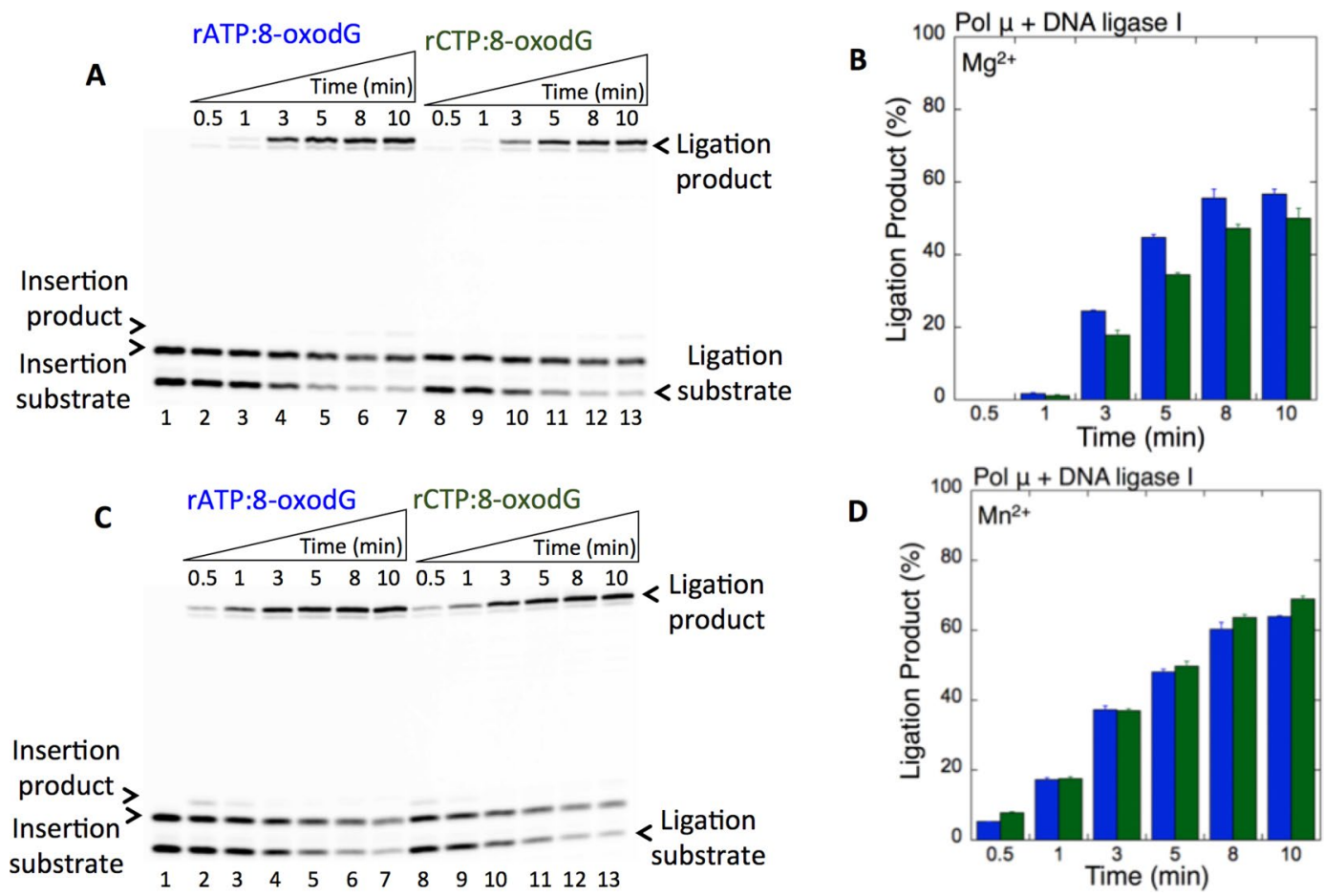

Figure 2. Pol $\mu$ rATP and $\mathrm{rCTP}$ insertion opposite 8-oxodG coupled with ligation by DNA ligase I in the presence of $\mathrm{Mg}^{2+}$ vs $\mathrm{Mn}^{2+}$. (A,C) In both panels, lane 1 is the minus enzyme control for the one nucleotide gapped DNA substrate with template 8-oxodG. Lanes 2-7 and 8-13 are the coupled reaction products in the presence of rATP or rCTP, respectively, and correspond to time points of $0.5,1,3,5,8$, and $10 \mathrm{~min}$. (B,D) Graphs show time-dependent changes in the products of ligation (blue for rATP:8-oxodG and green for rCTP:8-oxodG). The data represent the average of three independent experiments $\pm S D$. Corresponding uncropped gel images are shown in Supplementary Fig. 16.

Impact of $\mathrm{Mg}^{2+}$ vs $\mathrm{Mn}^{2+}$ on the ligation of pol $\mu$ ribonucleotide insertion products during mutagenic bypass of 8-oxodG. We next tested the idea that $\mathrm{Mn}^{2+}$, known as a mutagenic metal ion that improves the efficiency of NHEJ, might enable the more efficient ligation of the pol $\mu$ ribonucleotide insertion products ${ }^{25}$. For this purpose, the effect of $\mathrm{Mg}^{2+}$ vs $\mathrm{Mn}^{2+}$ on pol $\mu$ rATP or rCTP insertion coupled with ligation was evaluated.

In the presence of $\mathrm{Mg}^{2+}$, as described above, we obtained the ligation products after pol $\mu \mathrm{rATP}$ and $\mathrm{rCTP}$ insertions (Fig. 2A,B). Similarly, in the presence of $\mathrm{Mn}^{2+}$, the products of pol $\mu$ insertion of rATP (Fig. 2C, lanes 2-7) or rCTP (Fig. 2C, lanes 8-13) opposite 8-oxodG were efficiently ligated (Fig. 2D). However, in this case, the ligation products were slightly higher and accumulated at the earliest time point $(30 \mathrm{sec})$, in contrast to the appearance of ligation products at later time points (3-10 min) in the presence of $\mathrm{Mg}^{2+}$ (Supplementary Fig. 2). Similarly, we obtained ligation of pol $\mu$ rATP (Fig. 3A, lanes 2-7) and rCTP (Fig. 3A, lanes 8-13) insertions opposite 8-oxodG by the DNA ligase IV/XRCC4 complex (Fig. 3B). No significant difference was observed in the amount of ligation products between DNA ligase I vs the DNA ligase IV/XRCC4 complex (Supplementary Fig. 3).

To further understand the stimulatory effect of $\mathrm{Mn}^{2+}$ on pol $\mu$ ribonucleotide insertion coupled with ligation as described above, we repeated these coupled reactions for the early incubation time points $(10-60 \mathrm{sec})$. For both pol $\mu$ rATP:8-oxodG (Fig. 4A, lanes $2-5$ vs 6-9) and rCTP:8-oxodG (Fig. 4B, lanes $2-5$ vs 6-9) insertions, the amounts of ligation products were $\sim 5$-fold higher in the presence of $\mathrm{Mn}^{2+}$ than in the presence of $\mathrm{Mg}^{2+}$ (Fig. 4C,D). These results suggest a stimulatory role of $\mathrm{Mn}^{2+}$ in the channeling of the pol $\mu$ ribonucleotide insertion products from pol $\mu$ to the next DNA ligation step.

We also examined the ribonucleotide insertions into a single-nucleotide gap with a template 8-oxodG in a reaction mixture including pol $\mu$ alone (Supplementary Scheme 2) and obtained the differences in the insertion efficiency of rATP and rCTP in the presence of $\mathrm{Mg}^{2+} \mathrm{vs} \mathrm{Mn}^{2+}$ (Supplementary Fig. 4). These results showed that the ligation products observed in the coupled reactions including both pol $\mu$ and DNA ligase (Fig. 2) are due to the insertions by pol $\mu$ favoring $\mathrm{Mn}^{2+}$ over $\mathrm{Mg}^{2+}$ and their subsequent conversion to ligation products at the same time points of the reaction incubations. In the control reactions, we also confirmed the efficient conversion of the correct pol $\mu \mathrm{dNTP}$ insertion products, i.e., dATP opposite dT and dCTP opposite dG to complete ligation products (Supplementary Fig. 5). 

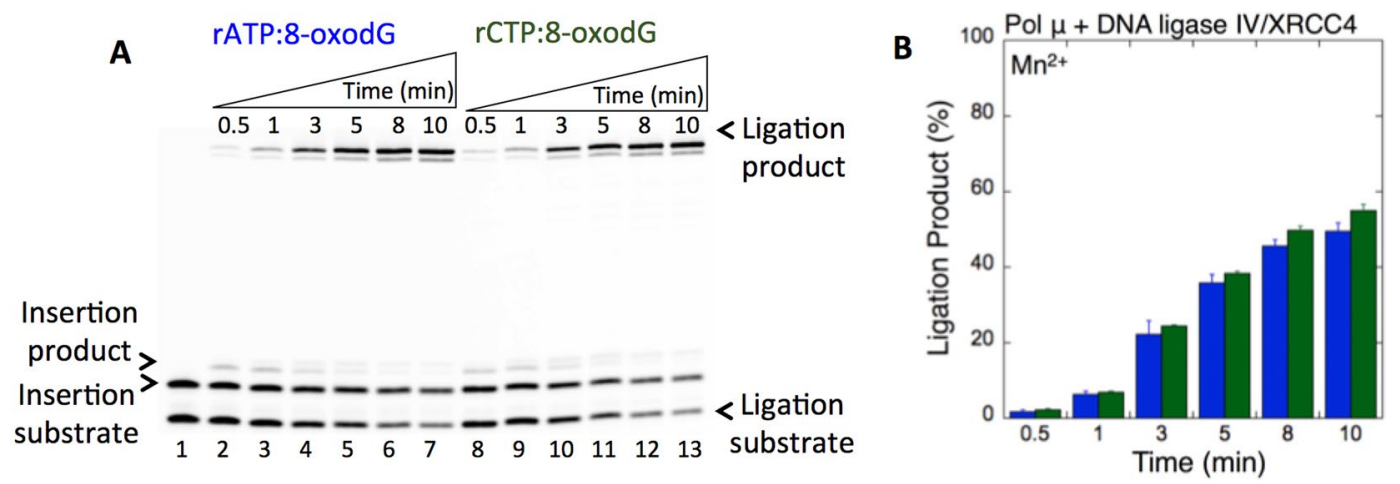

Figure 3. Pol $\mu$ rATP and rCTP insertion opposite 8-oxodG coupled with ligation by DNA ligase IV/XRCC4 complex in the presence of $\mathrm{Mn}^{2+}$. (A) Lane 1 is the minus enzyme control for the one nucleotide gapped DNA substrate with template 8-oxodG. Lanes 2-7 and 8-13 are the coupled reaction products in the presence of rATP or $\mathrm{rCTP}$, respectively, and correspond to time points of $0.5,1,3,5,8$, and $10 \mathrm{~min}$. (B) Graph shows timedependent changes in the products of ligation (blue for rATP:8-oxodG and green for rCTP:8-oxodG). The data represent the average of three independent experiments $\pm \mathrm{SD}$. Corresponding uncropped gel image is shown in Supplementary Fig. 17.

\section{A}
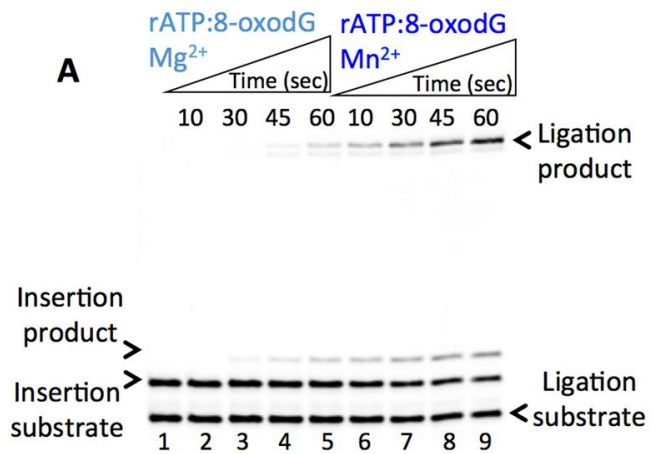

C

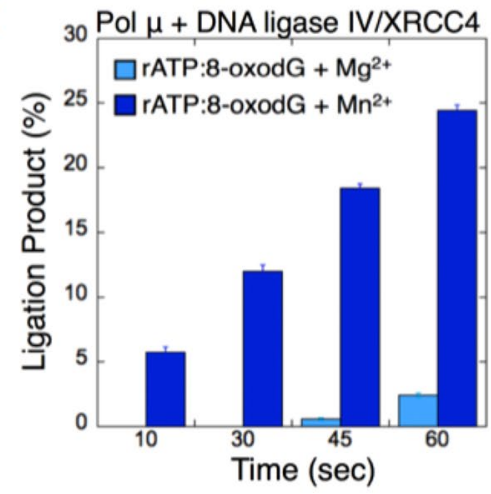

B

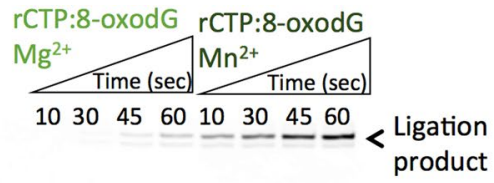

Insertion

product $>$

Insertion >- - - - - Ligation

substrate $\frac{1}{1}-\frac{1}{3}=\frac{7}{5} \frac{-}{6}-\frac{7}{7}-\frac{1}{9}<$ substrate

D

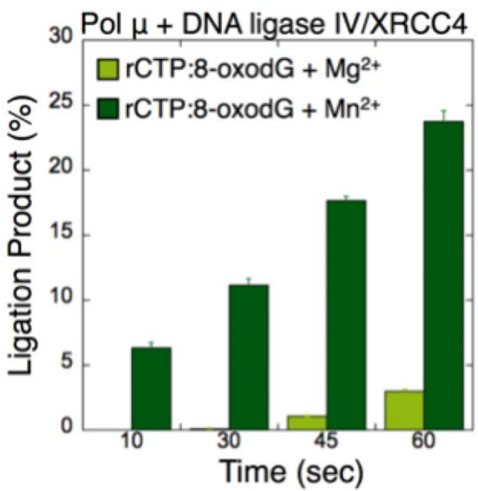

Figure 4. Pol $\mu$ rATP and rCTP insertion opposite 8-oxodG coupled with ligation by DNA ligase IV/XRCC4 complex in the presence of $\mathrm{Mg}^{2+}$ vs $\mathrm{Mn}^{2+}$. (A,B) In both panels, lane 1 is the minus enzyme control for the one nucleotide gapped DNA substrate with template 8-oxodG. Lanes 2-5 and 6-9 are the coupled reaction products in the presence of rATP and $\mathrm{Mg}^{2+}$ vs $\mathrm{Mn}^{2+}$ or in the presence of rCTP and $\mathrm{Mg}^{2+} \mathrm{vs} \mathrm{Mn}^{2+}$, respectively, and correspond to time points of 10, 30, 45, and $60 \mathrm{sec}$. (C,D) Graphs show the comparisons for the time-dependent changes in the products of ligation (blue for rATP:8-oxodG and green for rCTP:8-oxodG) in the presence of $\mathrm{Mg}^{2+}$ vs $\mathrm{Mn}^{2+}$. The data represent the average of three independent experiments $\pm \mathrm{SD}$. Corresponding uncropped gel images are shown in Supplementary Fig. 18.

Role of NHEJ structural elements and mutagenic bypass of 8-oxodG on the ligation of pol $\mu$ ribonucleotide insertion products. It has been reported that the recruitment of the NHEJ complex at DNA ends during DSB repair requires the presence of pol $\mu$ and DNA ligase IV in complex with XRCC4, and the BRCT 
A

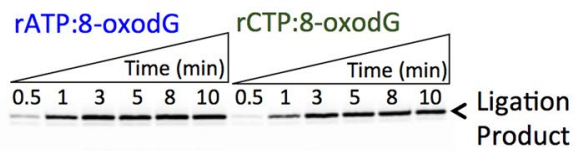

\section{Insertion}

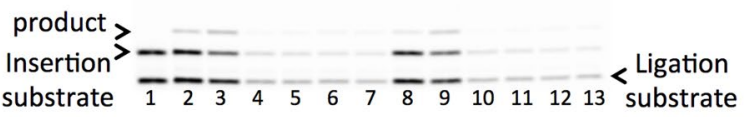

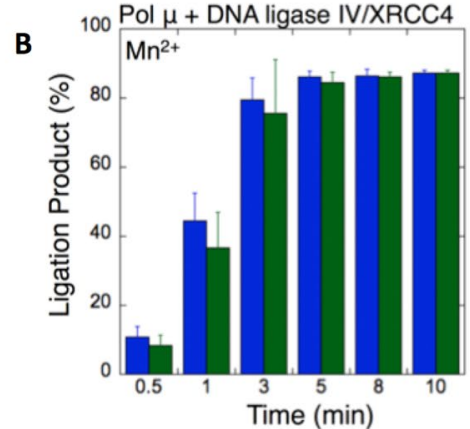

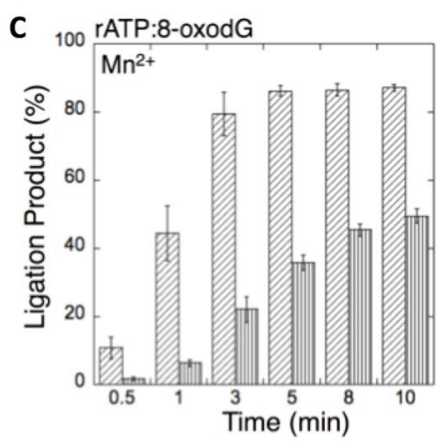

ÐFull-length pol $\mu+$ Lig IV/XRCC4

WCat domain of pol $\mu+$ Lig IV/XRCC4
D ${ }_{100}$ rCTP:8-oxodG

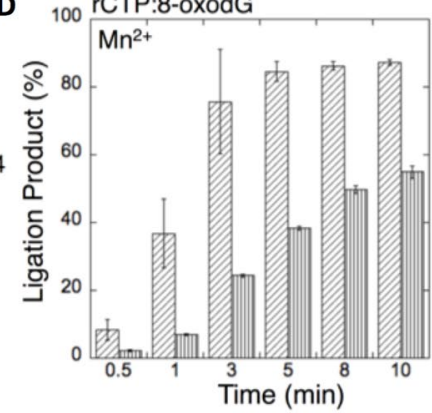

Figure 5. Full-length pol $\mu \mathrm{rATP}$ and $\mathrm{rCTP}$ insertion opposite 8-oxodG coupled with ligation by DNA ligase IV/XRCC4 complex. (A) Lane 1 is the minus enzyme control for the one nucleotide gapped DNA substrate with template 8-oxodG. Lanes $2-7$ and 8-13 are the coupled reaction products, and correspond to time points of 0.5 , $1,3,5,8$, and $10 \mathrm{~min}$. (B) Graph shows time-dependent changes in the products of ligation (blue for rATP:8oxodG and green for $\mathrm{rCTP}: 8$-oxodG). The data represent the average of three independent experiments \pm SD. (C,D) Graphs show the comparisons for the time-dependent changes in the products of ligation after rATP:8oxodG and rCTP:8-oxodG insertion by the full-length vs the catalytic domain of pol $\mu$. The data represent the average of three independent experiments \pm SD. Corresponding uncropped gel image is shown in Supplementary Fig. 19.

(BRCA1 C Terminus) domain of pol $\mu$ stabilizes the complex formation and promotes ligation independent of its gap-filling activity ${ }^{32,39,40}$. To further investigate the channeling of the ribonucleotide insertion products from pol $\mu$ to DNA ligase, we used the full-length pol $\mu$ and performed the coupled reactions in the presence of the DNA ligase IV/XRCC4 complex and $\mathrm{Mn}^{2+}$. Similarly, the results showed ligation of pol $\mu$ rATP (Fig. 5A, lanes 2-7) and rCTP (Fig. 5A, lanes 8-13) insertions and a time-dependent increase in the amounts of the products (Fig. 5B). However, the comparison of the coupled reactions revealed an enhanced ligation in the presence of the full-length pol $\mu$ including BRCT domain for both insertions (Fig. 5C,D). These findings suggest a coordinated hand off or interplay between pol $\mu$ and DNA ligase IV/XRCC4 complex in the multiprotein NHEJ complex for efficient ligation in the presence of ribonucleotides incorporated into DNA (Supplementary Model 1).

Moreover, to understand the impact of pol $\mu$ mutagenic bypass of 8-oxodG on ligation, we also used a single-nucleotide gapped DNA substrate with an undamaged guanine base (dG) at a template position (Supplementary Table 1) and compared the ligation efficiency of the pol $\mu$ ribonucleotide insertion products opposite 8-oxodG vs dG in the presence of $\mathrm{Mn}^{2+}$. The results revealed that the products of pol $\mu$ rATP:dG (Fig. 6A,C, lanes 2-7) and rCTP:dG (Fig. 6A,C, lanes 8-13) are efficiently ligated by DNA ligase I (Fig. 6B) and the DNA ligase IV/XRCC4 complex (Fig. 6D). Similarly, no significant difference was observed in the amount of ligation products between the DNA ligases (Supplementary Fig. 6). Interestingly, the comparison of the ligation products after pol $\mu$ rATP and rCTP insertion opposite 8-oxodG vs dG also shows no significant difference between the template bases (Supplementary Figs. 7 and 8 ). These results suggest that the pol $\mu$ active site can accommodate both 8-oxodG and $\mathrm{dG}$ in a similar way that enables the channeling of the ribonucleotide mismatch-containing repair intermediate from pol $\mu$ to DNA ligase for its efficient ligation. We also confirmed differences in the pol $\mu$ insertion efficiency of rATP and rCTP into a single-nucleotide gap with a template dG in the reaction mixture including pol $\mu$ alone (Supplementary Fig. 9).

Comparison of pol $\beta$-mediated ribonucleotide insertion coupled with ligation. It has been shown that pol $\beta$ can perform inefficient ribonucleotide insertion ( $\sim 4$ orders of magnitude less than dNTPs) during BER, and unlike pol $\mu$, the enzyme undergoes large conformational changes in protein subdomains upon dNTP binding or catalysis ${ }^{41-43}$. Moreover, the role of $\mathrm{pol} \beta$ in NHEJ has been reported ${ }^{44}$.

In this study, we also tested the effect of pol $\beta$ ribonucleotide insertion opposite 8-oxodG on ligation as described above for pol $\mu$. We obtained the pol $\beta$ insertion products of rATP:8-oxodG (Fig. 7A,C, lanes 3-7) and rCTP:8-oxodG (Fig. 7A,C, lanes 9-13) in the presence of $\mathrm{Mg}^{2+}$ or $\mathrm{Mn}^{2+}$ that were not completely ligated by 

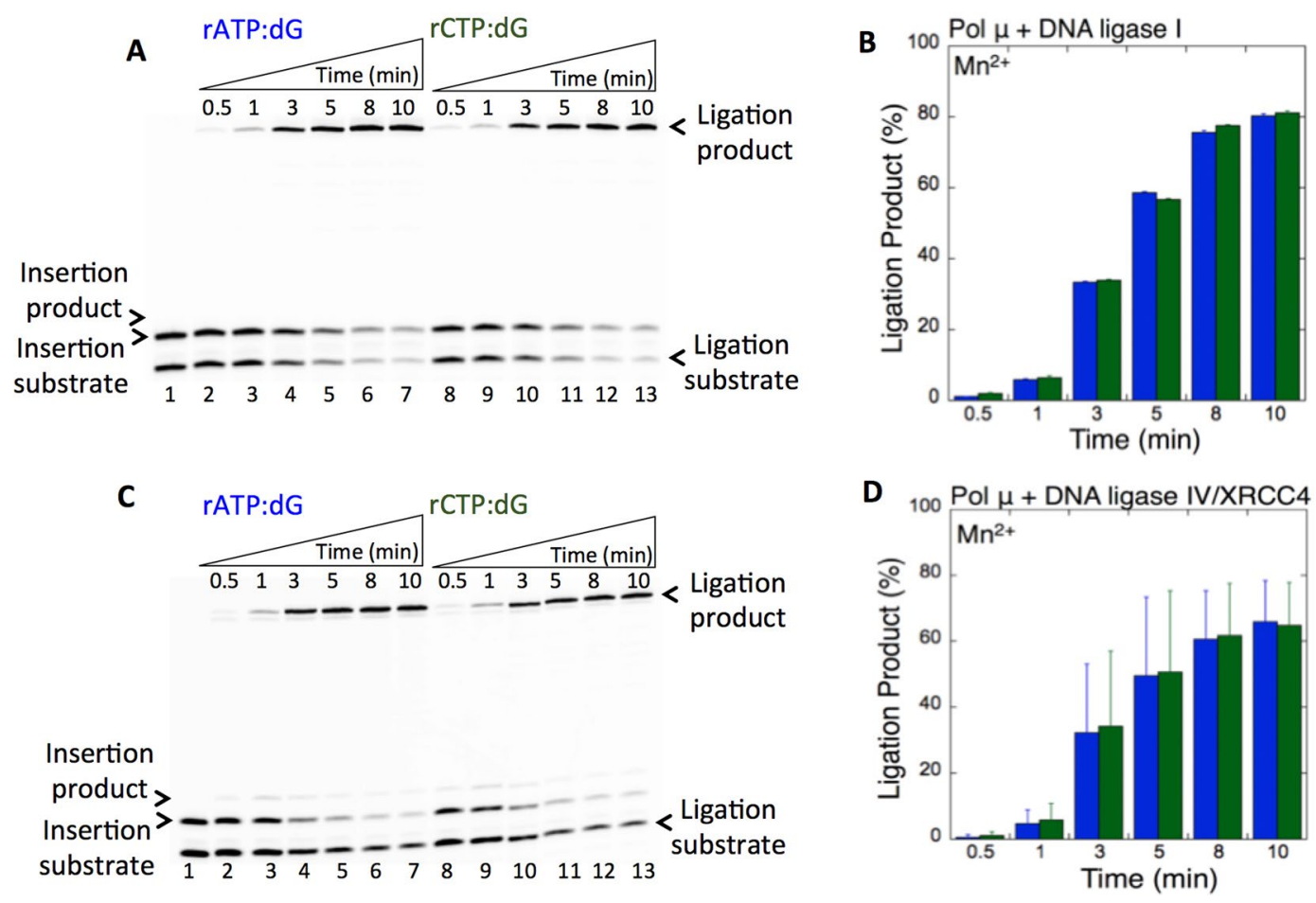

Figure 6. Pol $\mu$ rATP and rCTP insertion opposite dG coupled with ligation by DNA ligase I vs DNA ligase IV/ XRCC4 complex. $(\mathbf{A}, \mathbf{C})$ In both panels, lane 1 is the minus enzyme control for the one nucleotide gapped DNA substrate with template dG. Lanes 2-7 and 8-13 are the coupled reaction products in the presence of $\mathrm{rATP}$ or $\mathrm{rCTP}$, respectively, and correspond to time points of $0.5,1,3,5,8$, and $10 \mathrm{~min}$. (B,D) Graphs show timedependent changes in the products of ligation (blue for rATP:dG and green for rCTP:dG). The data represent the average of three independent experiments \pm SD. Corresponding uncropped gel images are shown in Supplementary Fig. 20.

DNA ligase I (Fig. 7B,D). There were $\sim 5$ - and $\sim 7$-fold differences in the amount of ligation products between the coupled reactions including pol $\beta$ vs pol $\mu$ in the presence of $\mathrm{Mg}^{2+}$ and $\mathrm{Mn}^{2+}$, (Supplementary Figs. 10 and 11), respectively. This inefficient channeling of the ribonucleotide-containing repair intermediate from pol $\beta$ to DNA ligase could be due to differences in the mechanism of sugar discrimination between these DNA polymerases during the bypass of 8-oxodG.

Effect of $3^{\prime}$-preinserted ribonucleotides on the efficiency of DNA ligation. We are also interested in examining the ligation of the repair intermediates with $3^{\prime}$-preinserted ribonucleotides in the presence of $\mathrm{Mn}^{2+}$ by DNA ligase alone (Supplementary Scheme 3). The nicked DNA substrates used here mimic the products of DNA polymerase-mediated ribonucleotide insertions and include $3^{\prime}$-rA or $3^{\prime}$-rC opposite 8-oxodG or dG (Supplementary Table 1).

We first tested the ligation efficiency of the nicked repair intermediates with $3^{\prime}$-rA or $3^{\prime}$-rC opposite 8-oxodG by DNA ligase I and the DNA ligase IV/XRCC4 complex. DNA ligase I was able to join the $3^{\prime}$-rA and $3^{\prime}$-rC ends (Fig. 8A, lanes 2-7 and 9-14, respectively) opposite 8-oxodG, as indicated by the time-dependent changes in the amounts of the ligation products (Fig. 8B). On the other hand, the DNA ligase IV/XRCC1 complex did not show similar activity for the nicked substrates with $3^{\prime}$-rA:8-oxodG (Fig. 8C, lanes 2-7) and 3'-rC:8-oxodG (Fig. 8C, lanes 9-14), and the amount of ligation products was lower (Fig. 8D). The comparison of the ligation products indicated an $\sim 4$ - to 6-fold difference between the DNA ligases tested in this study (Supplementary Fig. 12).

We then examined the specificity of the DNA ligases for the ligation of repair intermediates with preinserted $3^{\prime}$-rA or $3^{\prime}$-rC opposite dG. Interestingly, a significant difference ( 40 -fold more ligation products) in the mismatch specificity of DNA ligase I was observed for the repair intermediates with $3^{\prime}$-rC:dG (Fig. 9A, lanes 2-7) vs 3'-rA:dG (Fig. 9A, lanes 9-14). In both mismatches, products of ligation and ligation failure appeared simultaneously (Fig. 9B). On the other hand, the DNA ligase IV/XRCC4 complex showed almost no activity against the nicked substrates with $3^{\prime}$-rC:dG (Fig. 10A, lanes 2-7) and 3'-rA:dG (Fig. 10A, lanes 9-14), although a negligible amount of ligation failure products accumulated at later incubation time points (Fig. 10B). The comparison of the ligation products indicated a significant difference in the end joining ability of DNA ligase I vs the DNA ligase IV/XRCC4 complex for the nicked substrates with $3^{\prime}-\mathrm{rC}: \mathrm{dG}$ or $3^{\prime}-\mathrm{rA}: \mathrm{dG}$ (Supplementary Fig. 13). The results suggest that the DNA ligases tested in this study could be compromised by subtle changes in the noncanonical base pairs at the $3^{\prime}$-end or template base of the nicked repair intermediate. Our results indicated that the presence of 8-oxodG (Fig. 8), instead of dG (Figs. 9 and 10), at the template position resulted in complete ligation with no 

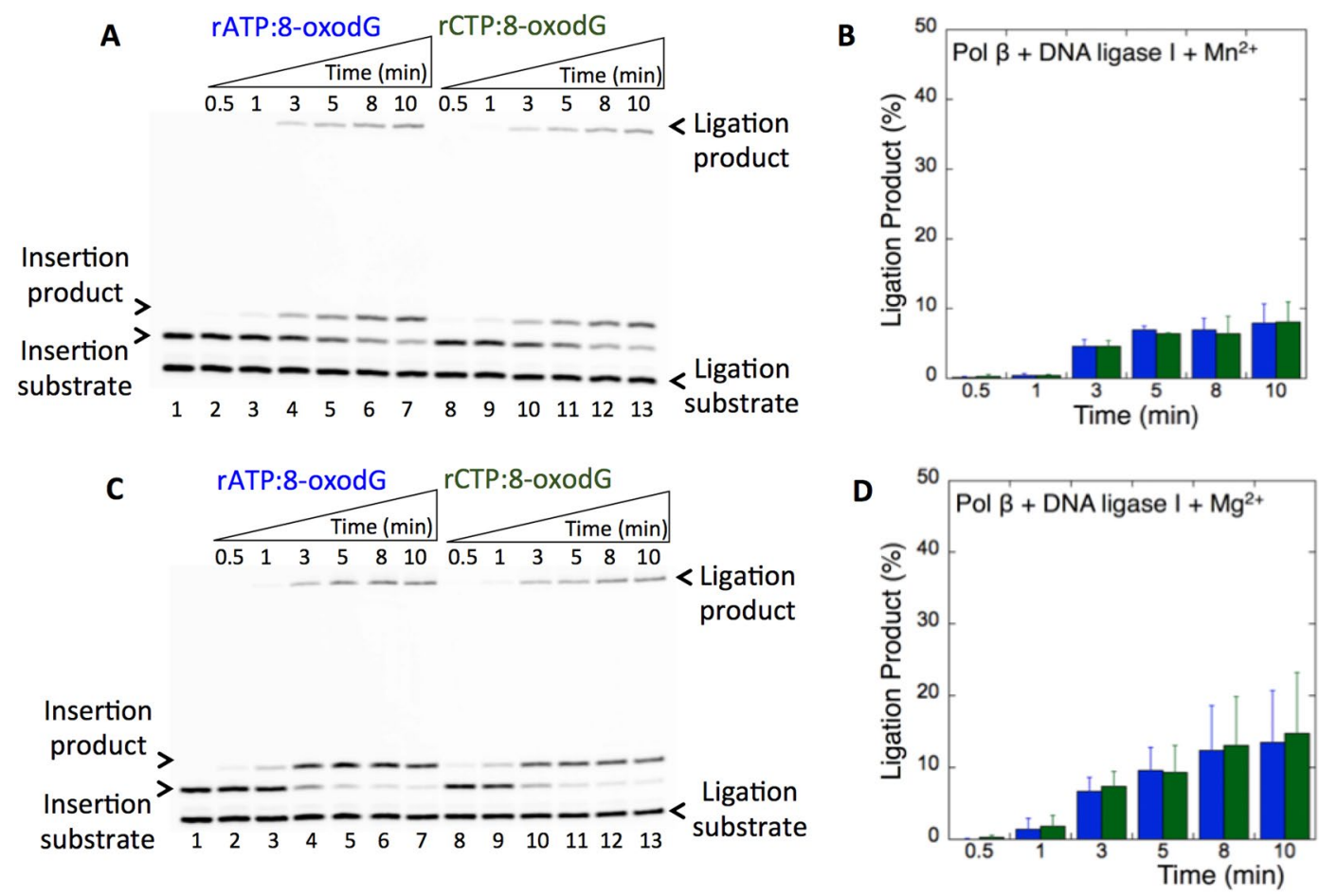

Figure 7. Pol $\beta$ rATP and rCTP insertion opposite 8-oxodG coupled with ligation by DNA ligase I in the presence of $\mathrm{Mg}^{2+}$ vs $\mathrm{Mn}^{2+}$. (A,C) In both panels, lane 1 is the minus enzyme control for the one nucleotide gapped DNA substrate with template 8-oxodG. Lanes 2-7 and 8-13 are the coupled reaction products in the presence of rATP or rCTP, respectively, and correspond to time points of $0.5,1,3,5,8$, and $10 \mathrm{~min}$. (B,D) Graphs show time-dependent changes in the products of ligation (blue for rATP:dG and green for rCTP:dG). The data represent the average of three independent experiments \pm SD. Corresponding uncropped gel images are shown in Supplementary Fig. 21.

failure. This could be due to the differences in the substrate and mismatch specificity of the DNA ligases and their end-joining ability of the non-canonical base pairs that mimic the nicked products of mismatch insertions by an error-prone DNA polymerase.

In the control reaction with the nicked DNA substrate containing $3^{\prime}$-preinserted correct base pairs, i.e., $3^{\prime}$-dA opposite $\mathrm{dT}$ and $3^{\prime}-\mathrm{dC}$ opposite $\mathrm{dG}$, we confirmed the ligation over incubation time of the reaction by DNA ligase I or the DNA ligase IV/XRCC4 complex (Supplementary Fig. 14).

The presence of pol $\mu$ mediates the ligation of ribonucleotide-containing NHEJ repair intermediates. Based on the observations described above, we finally compared the efficiency of ligation between the coupled reactions including pol $\mu$ and DNA ligase and the ligation assays containing DNA ligase alone. Overall, the results revealed that the amount of ligation products in the coupled reactions (i.e., ligation after pol $\mu$ rATP or rCTP insertion into a single-nucleotide gapped DNA substrate with template 8-oxodG or $\mathrm{dG}$ ) was higher than the amount of products in the ligation assays (i.e., ligation of the nicked DNA substrate with preinserted $3^{\prime}$-rA or $3^{\prime}$-rC opposite template 8-oxodG or dG), as shown in the black bar graphs in Figs. 11-14. The degree of difference in the amount of ligation products varied depending on the type of template base or DNA ligase used in this study, as summarized in Supplementary Table 2. Overall comparisons indicate that the insertion of ribonucleotides (rATP or rCTP) into DNA by pol $\mu$ is necessary for the ligation step and thus NHEJ to occur efficiently in vitro. On the other hand, the results also suggest that differences in the ligation efficiency of ribonucleotide-containing repair intermediates could be due to the distinct sugar and mismatch discrimination mechanisms of pol $\mu$ and DNA ligase, respectively, depending on the architecture of the DNA ends during NHEJ.

\section{Discussion}

The pool imbalance between the intracellular concentrations of rNTPs and dNTPs makes it challenging for RNA and DNA polymerases to select their correct sugar substrates ${ }^{1,2}$. Since the sugar-phosphate backbone of RNA is much more prone to strand breakage than that of DNA, potentially resulting in the accumulation of strand breaks, ribonucleotide insertion by DNA polymerases during replication and repair can constitute a major threat to genome stability ${ }^{3,4}$. The family X DNA polymerases, pol $\beta, \lambda$ and $\mu$, can incorporate rNTPs during the BER and NHEJ repair pathways with varying sugar selectivity ${ }^{10,11}$. These polymerases with no proofreading activity have also been shown to function in the translesion synthesis of oxidative DNA lesions such as 8-oxodG in an error-prone manner ${ }^{15-20}$. As a major oxidative base modification in DNA, 8-oxodG has a characteristic known as 


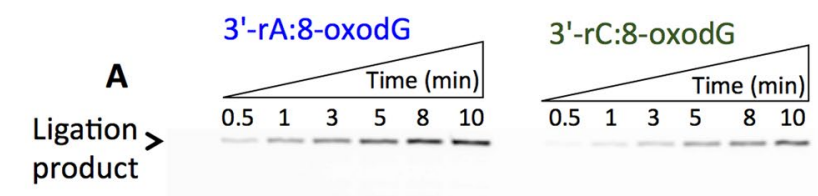

Ligation
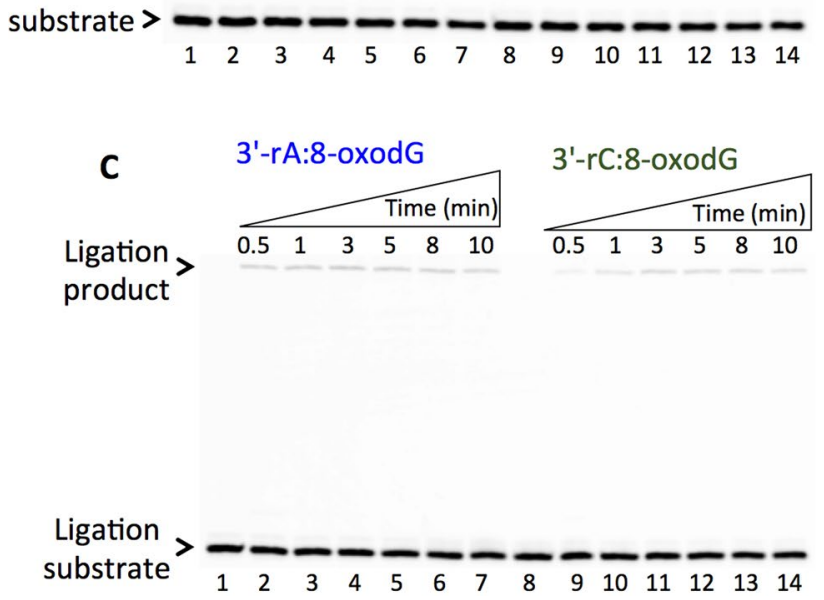
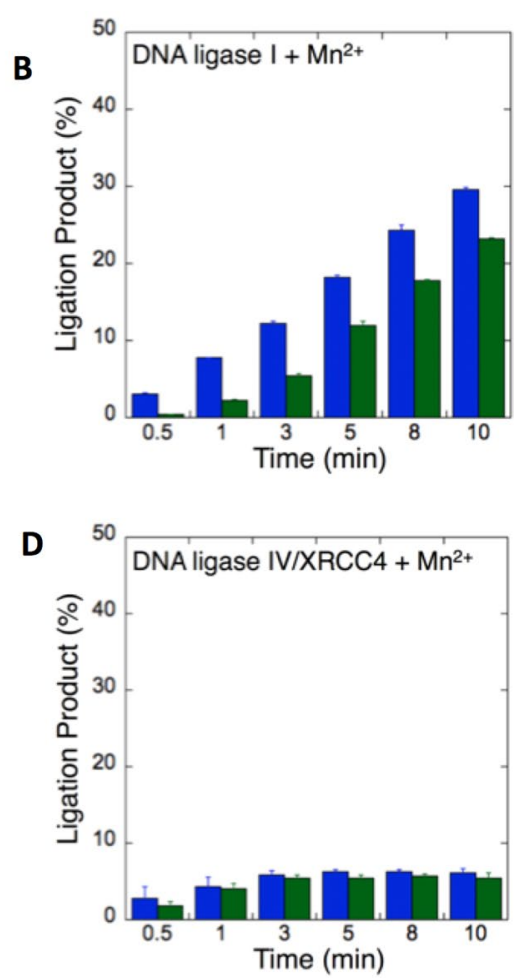

Figure 8. The ligation of preinserted $3^{\prime}$-rA and $3^{\prime}$-rC opposite 8-oxodG by DNA ligase I vs DNA ligase IV/ XRCC4 complex. (A,C) In both panels, lanes 1 and 8 are the minus enzyme controls for the nicked DNA substrates with $3^{\prime}$-rA:8-oxodG and 3'-rC:8-oxodG, respectively. Lanes 2-7 and 9-14 are the ligation products in the presence of $\mathrm{Mn}^{2+}$, and correspond to time points of $0.5,1,3,5,8$, and $10 \mathrm{~min}$. (B,D) Graphs show timedependent changes in the products of ligation (blue for 3'-rA:8-oxodG and green for 3'-rC:8-oxodG) by DNA ligase I (B) and DNA ligase IV/XRCC4 complex. (D) The data represent the average of three independent experiments \pm SD. Corresponding uncropped gel images are shown in Supplementary Fig. 22.

dual coding potential (in either the anti or syn conformation) that enables this base to form a correct base pairing with cytosine or a mispairing with adenine ${ }^{45}$. NHEJ, including several components of the repair machinery such as pol $\mu$ and the DNA ligase IV/XRCC4 complex, encounters this lesion in clusters at DNA strand break termini; however, the impact of pol $\mu$ ribonucleotide insertion during the translesion synthesis of 8-oxodG on the downstream ligation step of the repair pathway is unknown. $\mathrm{Mn}^{2+}$, as a mutagenic metal ion, is known to reduce DNA polymerase fidelity, and pol $\mu$ has a strong preference for $\mathrm{Mn}^{2+}$ over $\mathrm{Mg}^{2+}$ for its various activities, such as ribonucleotide insertion ${ }^{21-24}$. Moreover, it has been shown that physiological concentrations of $\mathrm{Mn}^{2+}$ and ribonucleotides enhance NHEJ with the cost of increased ribonucleotide insertion ${ }^{25}$. However, much less is known about the impact of the mutagenic metal ion on pol $\mu$ ribonucleotide insertion coupled with ligation during the NHEJ pathway.

We therefore investigated the ligation efficiency of pol $\mu$ ribonucleotide (rATP or rCTP) insertion products in the presence of a divalent ion $\left(\mathrm{Mg}^{2+}\right.$ or $\left.\mathrm{Mn}^{2+}\right)$ using a model NHEJ repair substrate with a template 8-oxodG in the coupled double-strand break repair catalyzed by pol $\mu$ and DNA ligase and compared it with that of the ligation reaction by DNA ligase alone in vitro. Our results indicated that pol $\mu$ stabilizes the insertion products of ribonucleotides (rATP or rCTP) over the insertion products of deoxyribonucleotides (dATP or dCTP) opposite 8-oxodG or $\mathrm{dG}$, allowing their efficient channeling to the next ligation step, which enables DNA ligase to function on the resulting nicked repair intermediate. On the other hand, the DNA ligases tested in this study (DNA ligase I and DNA ligase IV/XRCC4 complex) are compromised by noncanonical base pairings at the $3^{\prime}$-ends of the repair intermediates. The difference in our findings between a coupled reaction including pol $\mu$ and DNA ligase and the ligation reaction including DNA ligase alone (Figs. 11-14) revealed that the presence of ribonucleotides inserted by pol $\mu$ bypassing 8-oxodG is required for the efficient ligation of the repair intermediates in vitro. Our results demonstrate that pol $\mu$ ribonucleotide insertion during the translesion synthesis of 8-oxodG coupled with ligation could be a promutagenic event leading to genomic instability by NHEJ (Supplementary Model 1). Further research, that is, structure/function studies, will be necessary to enhance our understanding of the role of pol $\mu$ in the mutagenic potential of ribonucleotides embedded in genomic DNA. Similarly, in vivo studies will be required to understand the biological consequences of ribonucleotide incorporation in the oxidative stress-induced damage response during NHEJ in cells. 
A
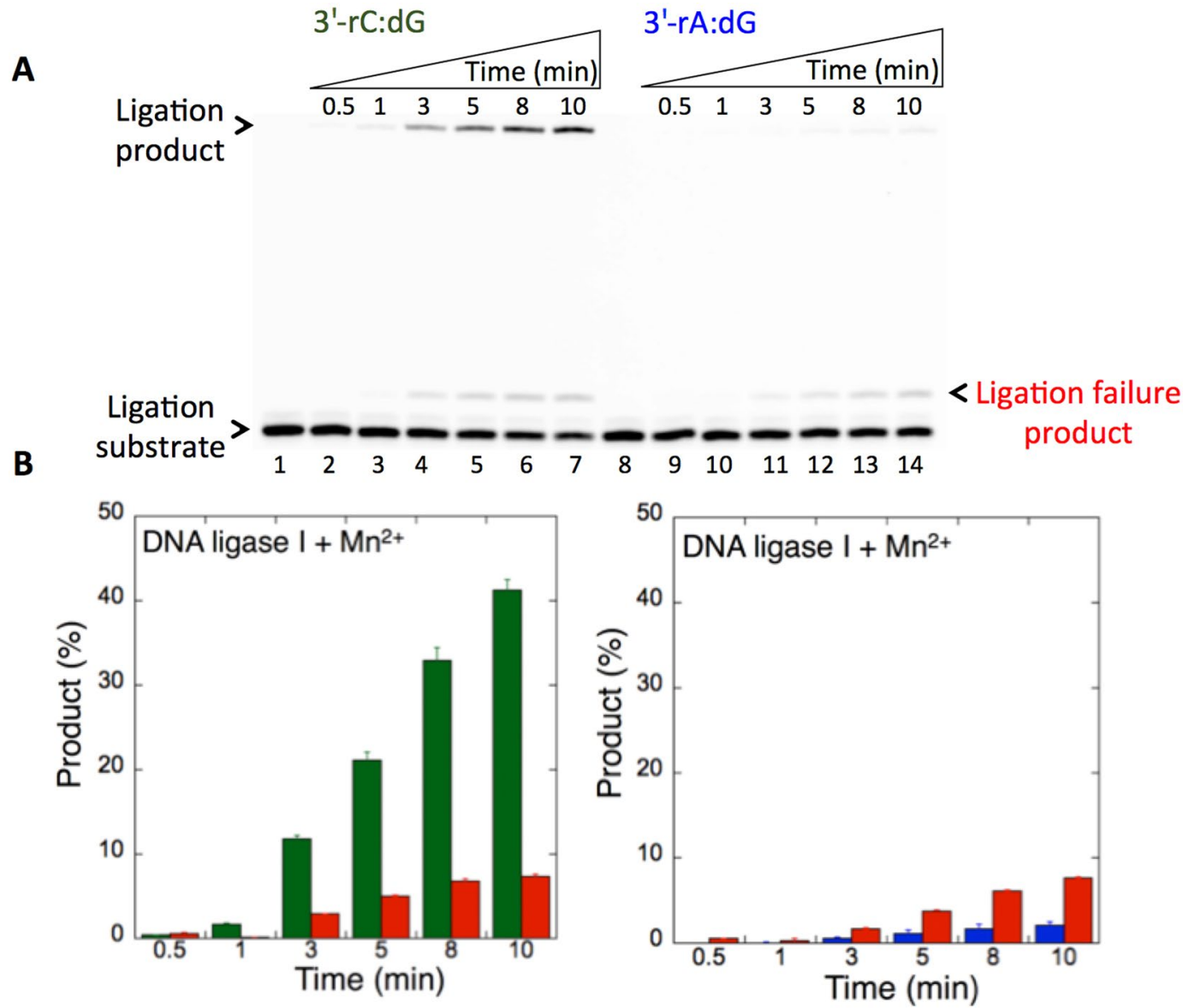

Figure 9. The ligation of preinserted $3^{\prime}$-rC and $3^{\prime}$-rA opposite dG by DNA ligase I. (A) Lanes 1 and 8 are the minus enzyme controls for the nicked DNA substrates with $3^{\prime}$-rC: $\mathrm{dG}$ and $3^{\prime}$-rA:dG, respectively. Lanes $2-7$ and 9-14 are the ligation products in the presence of $\mathrm{Mn}^{2+}$, and correspond to time points of $0.5,1,3,5,8$, and $10 \mathrm{~min}$. (B) Graphs show time-dependent changes in the products of ligation (blue for $3^{\prime}$-rA:dG and green for $3^{\prime}-\mathrm{rC}: \mathrm{dG}$ ) and ligation failure (red). The data represent the average of three independent experiments \pm SD. Corresponding uncropped gel image is shown in Supplementary Fig. 23.

\section{Materials and Methods}

Materials. Oligodeoxyribonucleotides with and without a 6-carboxyfluorescein (FAM) label were obtained from Integrated DNA Technologies. Single-nucleotide gapped and nicked DNA substrates (Supplementary Table 1) were prepared as described previously ${ }^{35,46}$. The deoxyribo- and ribonucleoside triphosphate solutions (dATP or rATP and dCTP or rCTP) were obtained from GE Healthcare.

Protein purifications. Human DNA polymerases, namely, full-length (Met1-Ala494) pol $\mu$, the catalytic domain (Pro132-Ala494) of pol $\mu$, and full-length pol $\beta$, were purified as described ${ }^{35,46-48}$. Briefly, the proteins were overexpressed in Rosetta2 (DE3) cells overnight at $16^{\circ} \mathrm{C}$. The cells were sonicated and lysed at $4{ }^{\circ} \mathrm{C}$ in lysis buffer containing $25 \mathrm{mM}$ Tris- $\mathrm{HCl}$ ( $\mathrm{pH} 8.0$ ), $500 \mathrm{mM} \mathrm{NaCl}, 5 \%$ glycerol, $1 \mathrm{mM}$ DTT, and cOmplete Protease Inhibitor Cocktail (Roche). The cell lysates were then clarified by centrifugation. The soluble proteins were bound to glutathione $4 \mathrm{~B}$ sepharose resin (GE Healthcare) at $4^{\circ} \mathrm{C}$, and the polymerases were eluted by TEV cleavage overnight at $4{ }^{\circ} \mathrm{C}$. The proteins were then purified by size exclusion chromatography (Superdex $20016 / 60$ ) followed by ion exchange (MonoQ HR 5/5) chromatography (GE Healthcare). The final proteins were dialyzed and concentrated in buffer containing $25 \mathrm{mM}$ Tris- $\mathrm{HCl}$ ( $\mathrm{pH} 8: 0), 100 \mathrm{mM} \mathrm{NaCl}, 5 \%$ glycerol, and $1 \mathrm{mM}$ DTT. Recombinant full-length human DNA ligase I was purified as previously described ${ }^{36,38,47}$. Briefly, the protein was expressed in Rosetta2 (DE3) cells at $37^{\circ} \mathrm{C}$, and the cells were grown overnight at $16^{\circ} \mathrm{C}$. After cell lysis by sonication at $4^{\circ} \mathrm{C}$ in lysis buffer containing $40 \mathrm{mM}$ HEPES (pH 7.5), $200 \mathrm{mM} \mathrm{NaCl}, 10 \%$ glycerol, and cOmplete Protease Inhibitor Cocktail (Roche) and clarification by centrifugation, the His-tagged protein was loaded onto a HisTrap HP column (GE Healthcare) and purified by elution with an increasing imidazole gradient $(0-500 \mathrm{mM})$ at $4{ }^{\circ} \mathrm{C}$, then subsequently loaded onto a HiTrap Q HP column (GE Healthcare) and eluted with NaCl. For all purified proteins used in this study, the final enzyme samples were concentrated, frozen in dry ice, and stored in aliquots at $-80^{\circ} \mathrm{C}$. 

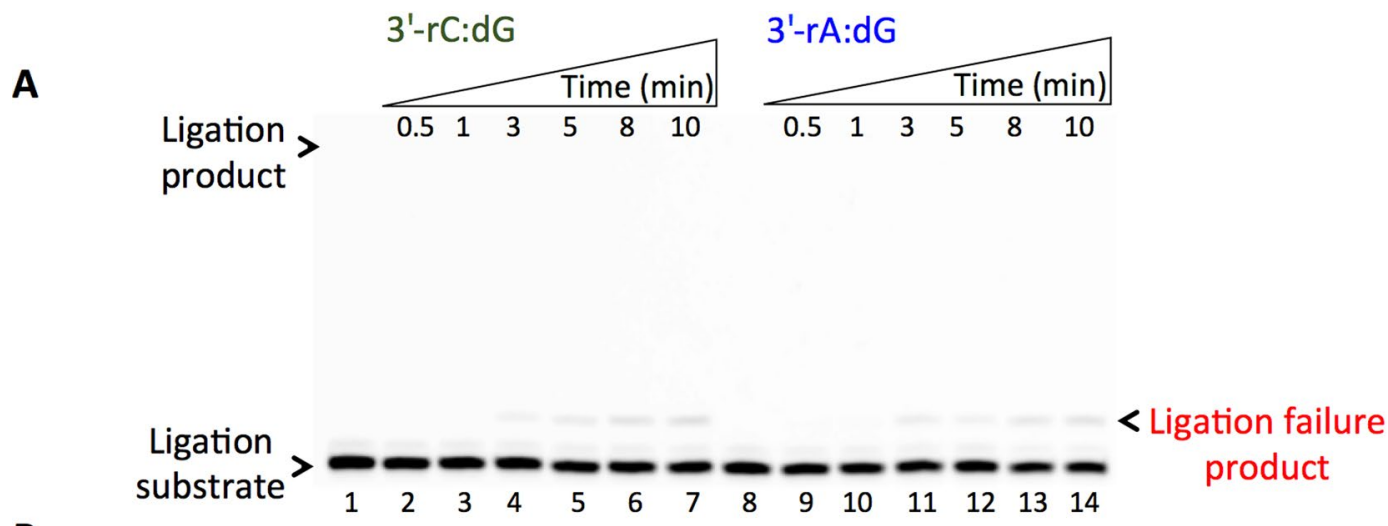

B
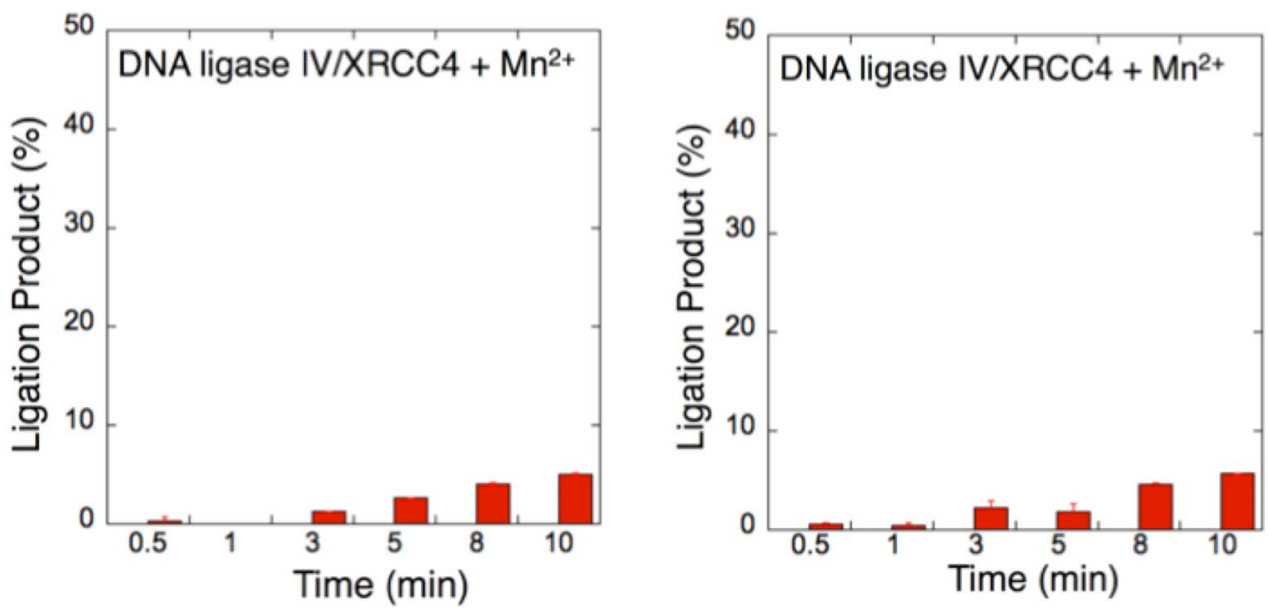

Figure 10. The ligation of preinserted $3^{\prime}$-rC and $3^{\prime}$-rA opposite dG by DNA ligase IV/XRCC4 complex. (A) Lanes 1 and 8 are the minus enzyme controls for the nicked DNA substrates with $3^{\prime}$-rC:dG and $3^{\prime}$-rA:dG, respectively. Lanes 2-7 and 9-14 are the ligation products in the presence of $\mathrm{Mn}^{2+}$ and correspond to time points of $0.5,1,3,5,8$, and $10 \mathrm{~min}$. (B) Graphs show time-dependent changes in the products of ligation (blue for $3^{\prime}-\mathrm{rA}: \mathrm{dG}$ and green for $3^{\prime}-\mathrm{rC}: \mathrm{dG}$ ) and ligation failure (red). The data represent the average of three independent experiments \pm SD. Corresponding uncropped gel image is shown in Supplementary Fig. 24.

Coupled reaction assay. The repair assays that enable the measurement of deoxyribonucleotide or ribonucleotide insertion coupled with ligation (Supplementary Scheme 1) were performed under steady-state conditions in vitro as described previously ${ }^{35,46}$. The single-nucleotide gapped DNA substrates with a template 8-oxodG or dG are presented in Supplementary Table 1. The reaction mixture contained $50 \mathrm{mM}$ Tris- $\mathrm{HCl}(\mathrm{pH} 7.5), 1 \mathrm{mM}$ DTT, $1 \mathrm{mM}$ ATP, $100 \mu^{-1 m l^{-1}} \mathrm{BSA}$, the single-nucleotide gapped DNA substrate $(500 \mathrm{nM}), 100 \mu \mathrm{M} \mathrm{rNTP}(\mathrm{rATP}$ or rCTP) or dNTP (dATP or dCTP), and $\mathrm{MgCl}_{2}(10 \mathrm{mM})$ or $\mathrm{MnCl}_{2}(1 \mathrm{mM})$ in a final volume of $10 \mu \mathrm{l}$. The reaction was initiated by the addition of the preincubated enzyme mixture, including DNA polymerase ( $p o l \mu$ or $\operatorname{pol} \beta$, $100 \mathrm{nM}$ ) and DNA ligase (DNA ligase I or DNA ligase IV/XRCC4 complex, $100 \mathrm{nM}$ ). The reaction mixtures were then incubated at $37^{\circ} \mathrm{C}$ for the times indicated in the figure legends. The reaction products were mixed with an equal amount of gel loading buffer ( $95 \%$ formamide, $20 \mathrm{mM} \mathrm{EDTA}, 0.02 \%$ bromophenol blue, and $0.02 \%$ xylene cyanol) and then separated by electrophoresis on an $18 \%$ polyacrylamide gel as described previously $y^{35,46}$. The gels were scanned with a Typhoon PhosphorImager (Amersham Typhoon RGB), and the data were analyzed with ImageQuant software. The control coupled reactions for pol $\mu$ correct base insertions (dATP:dT and dCTP:dG) were performed as described above.

Nucleotide insertion assay. The nucleotide insertion assays (Supplementary Scheme 2) were performed under steady-state conditions in vitro as described previously ${ }^{35,46}$. The single-nucleotide gapped DNA substrates with a template 8-oxodG or dG are presented in Supplementary Table 1. The reaction mixture contained $50 \mathrm{mM}$ Tris- $\mathrm{HCl}(\mathrm{pH} 7.5), 1 \mathrm{mM}$ DTT, $1 \mathrm{mM}$ ATP, $100 \mathrm{\mu gml}^{-1} \mathrm{BSA}$, the single-nucleotide gapped DNA substrate $(500 \mathrm{nM}), 100 \mu \mathrm{M}$ rNTP $(\mathrm{rATP}$ or $\mathrm{rCTP})$ and $\mathrm{MgCl}_{2}(10 \mathrm{mM})$ or $\mathrm{MnCl}_{2}(1 \mathrm{mM})$ in a final volume of $10 \mu \mathrm{ll}$. The reaction was initiated by the addition of pol $\mu$, and the reaction mixtures were then incubated at $37^{\circ} \mathrm{C}$ for the time points indicated in the figure legends. The reaction products were mixed with an equal amount of gel loading buffer (95\% formamide, $20 \mathrm{mM}$ EDTA, $0.02 \%$ bromophenol blue, and $0.02 \%$ xylene cyanol) and then separated and analyzed as described above. 

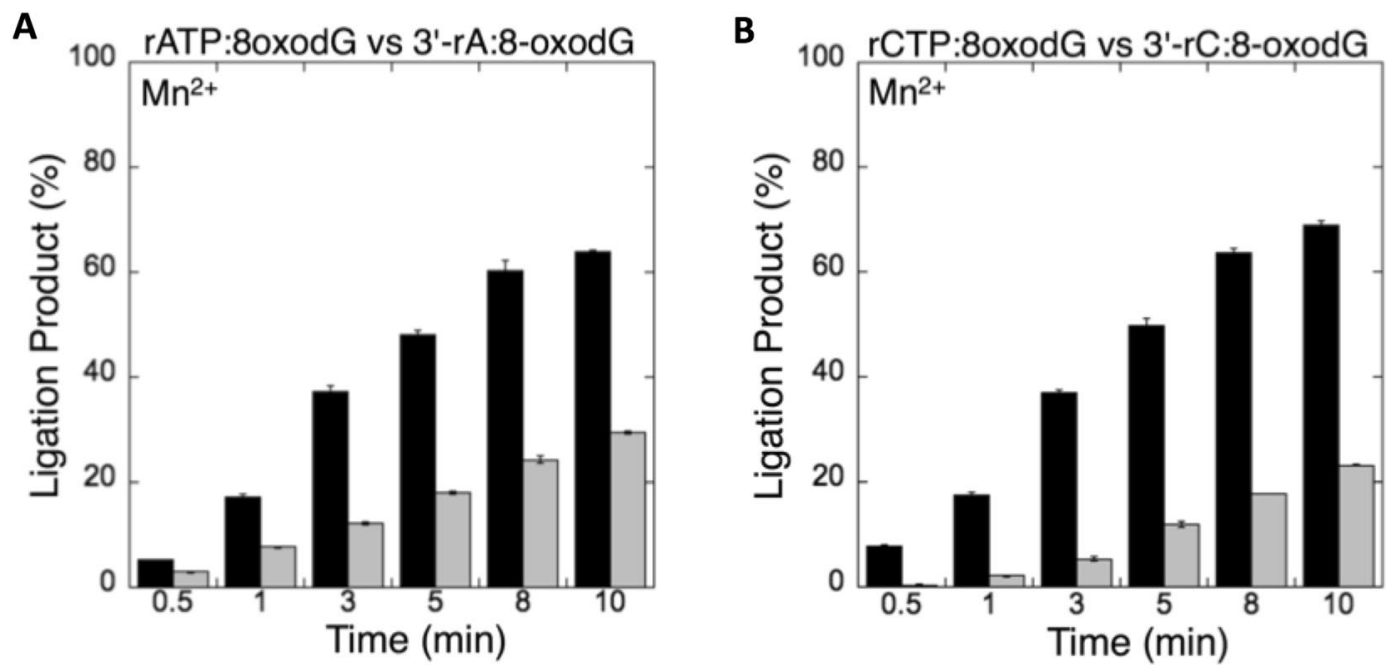

\section{Coupled vs Ligation \\ Dol $\mu$ + DNA ligase I \\ 口DNA ligase I}

Figure 11. Coupled vs ligation for pol $\mu$ and DNA ligase I in the presence of template 8-oxodG. Graphs show the comparisons for the time-dependent changes in the products of ligation between the coupled and ligation reactions for rATP:8-oxodG vs 3'-rA:8-oxodG (A) and rCTP:8-oxodG vs 3'-rC:8-oxodG (B). The data represent the average of three independent experiments \pm SD.
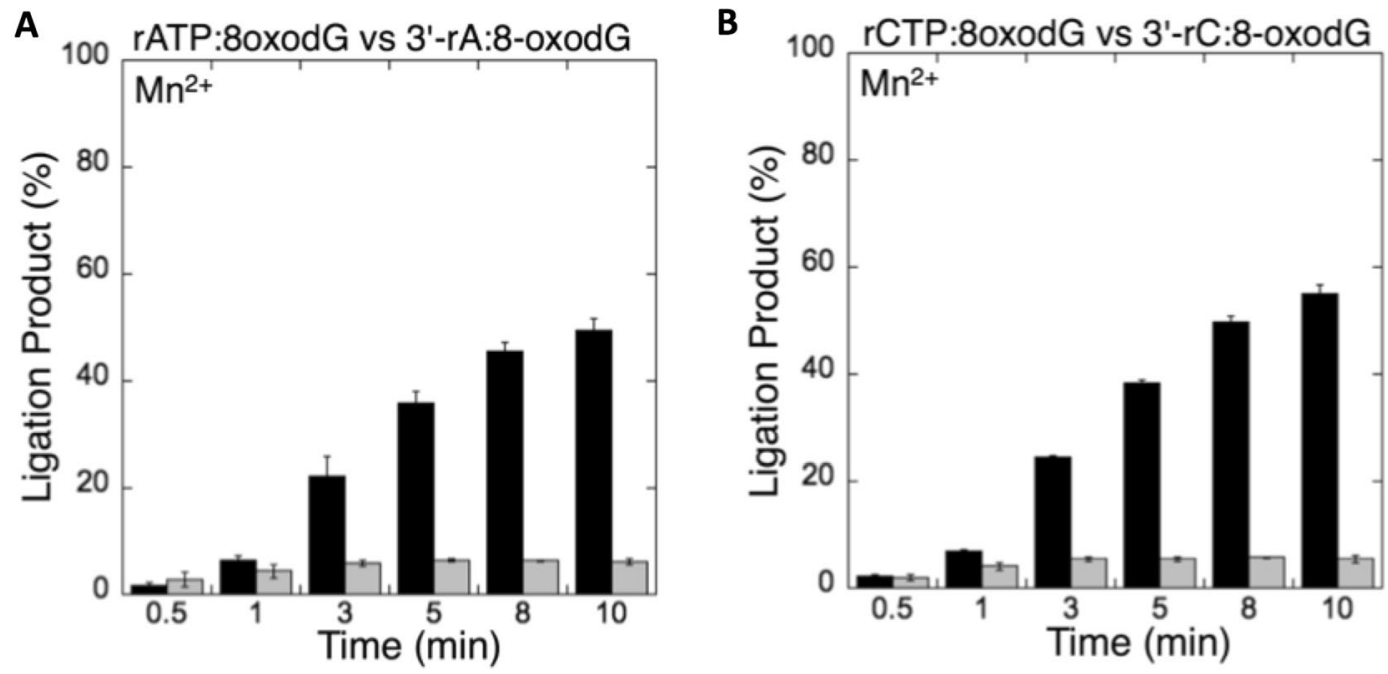

\section{Coupled vs Ligation \\ - Pol $\mu$ + DNA ligase IV/XRCC4 \\ DNA ligase IV/XRCC4}

Figure 12. Coupled vs ligation for pol $\mu$ and DNA ligase IV/XRCC4 complex in the presence of template 8-oxodG. Graphs show the comparisons for the time-dependent changes in the products of ligation between the coupled and ligation reactions for rATP:8-oxodG vs 3'-rA:8-oxodG (A) and rCTP:8-oxodG vs 3'-rC:8-oxodG (B). The data represent the average of three independent experiments \pm SD. 

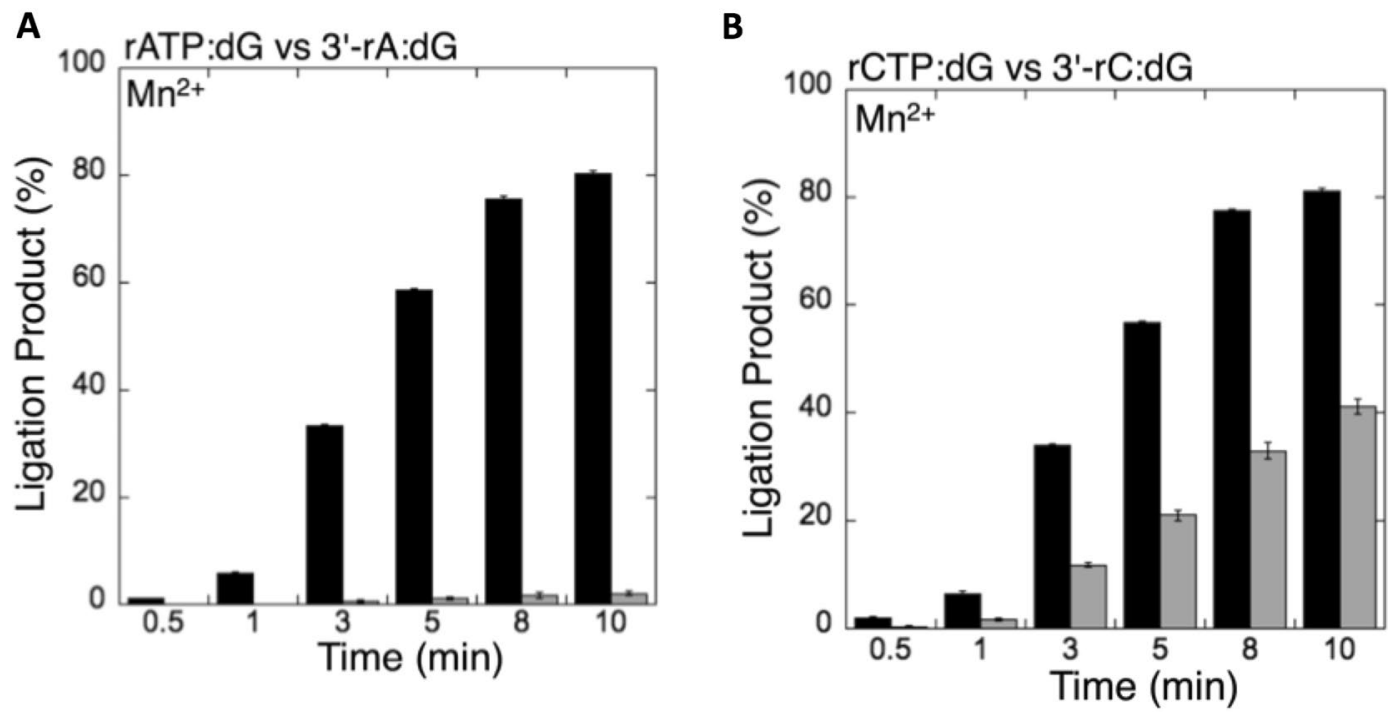

\section{Coupled vs Ligation \\ - Pol $\mu$ + DNA ligase I \\ DNA ligase I}

Figure 13. Coupled vs ligation for pol $\mu$ and DNA ligase I in the presence of template dG. Graphs show the comparisons for the time-dependent changes in the products of ligation between the coupled and ligation reactions for rATP:dG vs 3'-rA:dG (A) and rCTP:dG vs 3'-rC:dG (B). The data represent the average of three independent experiments \pm SD.

A

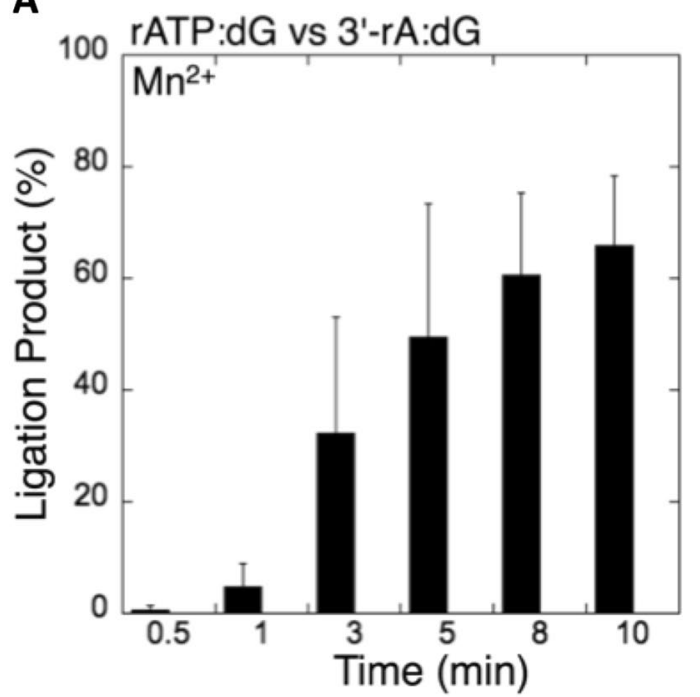

B

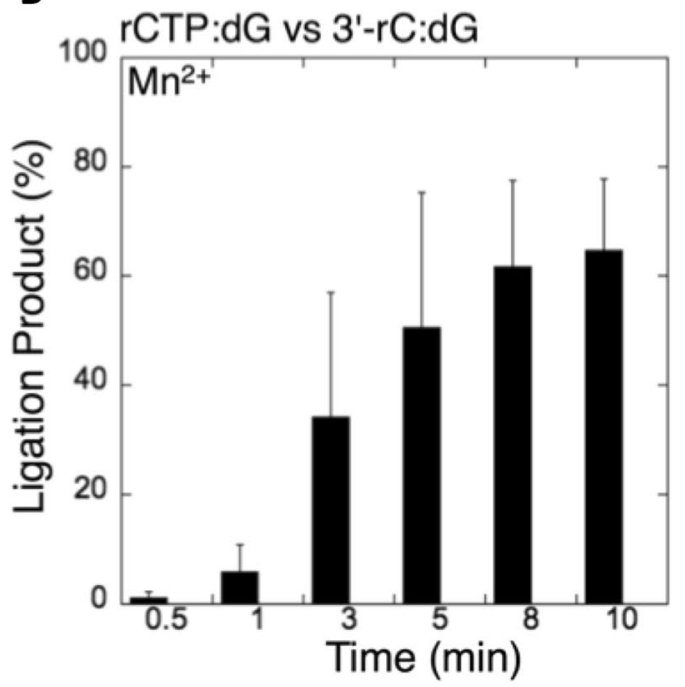

Coupled vs Ligation

口Pol $\mu$ + DNA ligase IV/XRCC4

$\square$ DNA ligase IV/XRCC4

Figure 14. Coupled vs ligation for pol $\mu$ and DNA ligase IV/XRCC4 complex in the presence of template dG. Graphs show the comparisons for the time-dependent changes in the products of ligation between the coupled and ligation reactions for rATP:dG vs $3^{\prime}$-rA:dG (A) and rCTP:dG vs $3^{\prime}-\mathrm{rC}: \mathrm{dG}(\mathbf{B})$. The data represent the average of three independent experiments \pm SD. 
Ligation assay. The ligation assays (Supplementary Scheme 3) were performed under steady-state conditions in vitro as described previously ${ }^{35,46}$. The nicked DNA substrates with $3^{\prime}$-preinserted ribonucleotides $\left(3^{\prime}\right.$-rA or $3^{\prime}-\mathrm{rC}$ ) opposite 8-oxodG or dG are presented in Supplementary Table 1 . The reaction mixture contained $50 \mathrm{mM}$ Tris- $\mathrm{HCl}$ (pH 7.5), $1 \mathrm{mM}$ DTT, $1 \mathrm{mM}$ ATP, $100 \mu \mathrm{gml}^{-1}$ BSA, the nicked DNA substrate $(500 \mathrm{nM})$ and $\mathrm{MgCl}_{2}(10 \mathrm{mM})$ or $\mathrm{MnCl}_{2}(1 \mathrm{mM})$ in a final volume of $10 \mu \mathrm{l}$. The experiments were initiated with the addition of DNA ligase (DNA ligase I or DNA ligase IV/XRCC4 complex, $100 \mathrm{nM}$ ). The reaction mixture was incubated at $37^{\circ} \mathrm{C}$ until the time points indicated in the figure legends and then stopped by mixing with an equal volume of loading dye. The reaction products were analyzed as described above. Control ligation assays with nicked DNA substrates, including correct base pairs ( $3^{\prime}-\mathrm{dA}: \mathrm{dT}$ and $\left.3^{\prime}-\mathrm{dC}: \mathrm{dG}\right)$, were performed as described above.

Received: 21 October 2019; Accepted: 7 January 2020;

Published online: 22 January 2020

\section{References}

1. Klein, H. L. Genome instabilities arising from ribonucleotides in DNA. DNA Repair 56, 26-32 (2017),

2. Potenski, C. J. \& Klein, H. L. How the misincorporation of ribonucleotides into genomic DNA can be both harmful and helpful to cells. Nuc. Acids Res. 42, 10226-10234 (2014).

3. Sassa, A., Yasui, M. \& Honma, M. Current perspectives on mechanisms of ribonucleotide incorporation and processing in mammalian DNA. Genes Environ. 41, 3 (2019).

4. Yao, N. Y., Schroeder, J. W., Yurieva, O., Simmons, L. A. \& O’Donnell, M. E. Cost of rNTP/dNTP pool imbalance at the replication fork. Proc. Natl. Acad. Sci. 110, 12942-12947 (2013).

5. Khanna, K. K. \& Jackson, S. P. DNA double-strand breaks: signaling, repair and the cancer connection. Nat. Genet. 27, 247-254 (2001).

6. Ma, Y., Lu, H., Schwarz, K. \& Lieber, M. R. Repair of double-strand DNA breaks by the human nonhomologous DNA end joining pathway: the iterative processing model. Cell Cycle 4, 1193-1200 (2005)

7. Chayot, R., Montagne, B. \& Ricchetti, M. DNA polymerase $\mu$ is a global player in the repair of non-homologous end-joining substrates. DNA Repair 11, 22-34 (2012).

8. McElhinny, S. A. \& Ramsden, D. A. Polymerase $\mu$ is a DNA-directed DNA/RNA polymerase. Mol. Cell Biol. 23, 2309-2315 (2003).

9. Chayot, R., Danckaert, A., Montagne, B. \& Ricchetti, M. Lack of DNA polymerase $\mu$ affects the kinetics of DNA double-strand break repair and impacts on cellular senescence. DNA Repair 9, 1187-1199 (2010).

10. Brown, J. A. et al. A novel mechanism of sugar selection utilized by a human X-family DNA polymerase. J. Mol. Biol. 395, 282-290 (2010).

11. Brown, J. A. \& Suo, Z. Unlocking the sugar 'steric gate' of DNA polymerases. Biochemistry 50, 1135-1142 (2011).

12. Moon, A. F. et al. Structural accommodation of ribonucleotide incorporation by the DNA repair enzyme polymerase $\mu$. Nuc. Acids Res. 45, 9138-9148 (2017).

13. Ruiz, J. F. et al. Lack of sugar discrimination by human pol $\mu$ requires a single glycine residue. Nuc. Acids Res. 31, 4441-4449 (2014).

14. Moon, A. F. et al. Sustained active site rigidity during synthesis by human DNA polymerase $\mu$. Nat. Struct. Mol. Biol. 21, 253-260 (2014).

15. Covo, S., Blanco, L. \& Livneh, Z. Lesion bypass by human DNA polymerase $\mu$ reveals a template-dependent, sequence-independent nucleotidyl transferase activity. J. Biol. Chem. 279, 859-865 (2004).

16. Dominguez, O. et al. DNA polymerase $\mu$, homologous to TdT, could act as a DNA mutator in eukaryotic cells. EMBO J. 19, $1731-1742$ (2000).

17. Havener, J. M. et al. Translesion synthesis past platinum DNA adducts by human DNA polymerase $\mu$. Biochemistry 43, 1777-1788 (2003).

18. Ruiz, J. F. et al. DNA polymerase $\mu$, a candidate hypermutase? Philos. Trans. R. Soc. Lond. B. Biol. Sci. 356, 99-109 (2001).

19. Zhang, Y. et al. Lesion bypass activities of human DNA polymerase $\mu$. J. Biol. Chem. 277, 44582-44587 (2002).

20. Kaminski, A. M. et al. Unexpected behavior of DNA polymerase $\mu$ opposite template 8-oxo-7,8-dihydro-2'-guanosine. Nuc. Acids Res. 47, 9410-9422 (2019).

21. Sirover, M. A. \& Loeb, L. A. Infidelity of DNA synthesis in vitro: screening for potential metal mutagens or carcinogens. Science 194, 1434-1436 (1976).

22. Goodman, M. F., Keener, S., Guidotti, S. \& Branscomb, E. W. On the enzymatic basis for mutagenesis by manganese. J. Biol. Chem. 258, 3469-3475 (1983).

23. Beckman, R. A., Mildvan, A. S. \& Loeb, L. A. On the fidelity of DNA replication: manganese mutagenesis in vitro. Biochemistry 24, 5810-5817 (1985).

24. Hays, H. \& Berdis, A. J. Manganese substantially alters the dynamics of translesion DNA synthesis. Biochemistry 41, 4771-4778 (2002).

25. Martin, M. J., Ortiz-Garcia, M. V., Esteban, V. \& Blanco, L. Ribonucleotides and manganese ions improve non-homologous end joining by human pol $\mu$. Nuc. Acids Res. 41, 2428-2436 (2013).

26. Chang, Y. K. et al. Human DNA polymerase $\mu$ can use a nancanonical mechanism for multiple $\mathrm{Mn}^{2+}$-mediated functions. J. Am. Chem. Soc. 141, 8489-8502 (2019).

27. Waters, C. A., Strande, N. T., Wyatt, D. W., Pryor, J. M. \& Ramsden, D. A. Nonhomologous end joining: a good solution for bad ends. DNA Repair 17, 39-51 (2014).

28. Lieber, M. R. The mechanism of human nonhomologous DNA end joining. J. Biol. Chem. 283, 1-5 (2008).

29. Martin, M. J. \& Blanco, L. Decision-making during NHEJ: a network of interactions in human pol $\mu$ implicated in substrate recognition and end-bridging. Nuc. Acids Res. 42, 7923-7934 (2014).

30. Kuhfittig-Kulle, S. et al. The mutagenic potential of non-homologous end joining in the absence of the NHEJ core factors Ku70/80, DNA-PKcs and XRCC4-LigIV. Mutagenesis 22, 217-233 (2007).

31. Davis, B., Havener, J. M. \& Ramsden, D. A. End-bridging is required for pol $\mu$ to efficiently promote repair of noncomplementary ends by nonhomologous end joining. Nuc. Acids Res. 36, 3085-3094 (2008).

32. Mahajan, K. N., McElhinny, S. A., Mitchell, B. S. \& Ramsden, D. A. Association of DNA polymerase $\mu$ with Ku and Ligase IV: Role for pol $\mu$ in end-joining double-strand break repair. Mol. Cell. Biol. 22, 5194-5202 (2002).

33. Waters, C. A. et al. The fidelity of the ligation step determines how ends are resolved during nonhomologous end joining. Nat. Commun. 5, 4286 (2014).

34. Conlin, M. P. et al. DNA Ligase IV guides end-processing choice during nonhomologous end joining. Cell Rep. 20, 2810-2819 (2017).

35. Cağlayan, M. \& Wilson, S. H. Pol $\mu$ dGTP mismatch insertion opposite T coupled with ligation reveals a promutagenic DNA intermediate during double strand break repair. Nat. Commun. 9, 4213 (2018). 
36. Çağlayan, M. \& Wilson, S. H. Oxidant and environmental toxicant-induced effects compromise DNA ligation during base excision DNA repair. DNA Repair 35, 85-89 (2015).

37. Cağlayan, M. Interplay between DNA polymerases and DNA ligases: Influence on substrate channeling and the fidelity of DNA ligation. J. Mol. Biol. 31, 2068-2081 (2019).

38. Pryor, J. M. et al. Ribonucleotide incorporation enables repair of chromosome breaks by nonhomologous end joining. Science 361, $1126-1129$ (2018).

39. Ramden, D. A. Polymerases in nonhomologous end joining: Building a bridge over broken chromosomes. Antioxid. Redox Signal 14, 2509-2019 (2011).

40. Tseng, H. M. \& Tomkinson, A. E. A physical and functional interaction between yeast Pol4 and Dnl4-Lif1 links DNA synthesis and ligation in nonhomologous end joining. J. Biol. Chem. 277, 45630-45637 (2002).

41. Crespan, E. et al. Impact of ribonucleotide incorporation by DNA polymerases $\beta$ and $\lambda$ on oxidative base excision repair. Nat. Comm. 7, 10805 (2016).

42. Cavanaugh, N. A., Beard, W. A. \& Wilson, S. H. DNA polymerase $\beta$ ribonucleotide discrimination. J. Biol. Chem. 285, 24457-24465 (2010).

43. Pelletier, H., Sawaya, M. R., Wolfle, W., Wilson, S. H. \& Kraut, J. A Structural basis for metal ion mutagenicity and nucleotide selectivity in human DNA polymerase 3 . Biochemistry 35, 12762-12777 (1996).

44. Ray, S. et al. DNA polymerase beta participates in DNA end-joining. Nucleic Acids Res. 46, 242-255 (2018).

45. Kamiya, H. Mutagenic potentials of damaged nucleic acids produced by reactive oxygen/nitrogen species: approaches using synthetic oligonucleotides and nucleotides: survey and summary. Nucleic Acids Res. 31, 517-531 (2003).

46. Çağlayan, M., Horton, J. K., Stefanick, D. F. \& Wilson, S. H. Oxidized nucleotide insertion by pol $\beta$ confounds ligation during base excision repair. Nat. Commun. 8, 14045 (2017).

47. Beard, W. A. \& Wilson, S. H. Purification and domain-mapping of mammalian DNA polymerase beta. Methods in Enzymology 262, 98-107 (1995).

48. Howes, T. R. L. et al. Structure-activity relationships among DNA ligase inhibitors: Characterization of a selective uncompetitive DNA ligase I inhibitor. DNA Repair 60, 29-39 (2017).

\section{Acknowledgements}

The purified protein human DNA ligase IV/XRCC4 complex and the plasmid expression vector for human DNA ligase I were generous gifts from Alan E. Tomkinson (University of New Mexico). The plasmid expression vectors for the human DNA polymerase $\beta$ (full-length) and DNA polymerase $\mu$ (hPol $\mu \Delta 2$ truncated catalytic domain) were from Samuel H. Wilson and Lars Pedersen (NIEHS/NIH), respectively. This work was supported by the National Institutes of Health/National Institute of Environmental Health Sciences Grant 4R00ES026191.

\section{Author contributions}

The author (MELIKE CAGLAYAN) designed the project, performed the experiments, and wrote the manuscript.

\section{Competing interests}

The author declares no competing interests.

\section{Additional information}

Supplementary information is available for this paper at https:/doi.org/10.1038/s41598-020-57886-y.

Correspondence and requests for materials should be addressed to M.Ç.

Reprints and permissions information is available at www.nature.com/reprints.

Publisher's note Springer Nature remains neutral with regard to jurisdictional claims in published maps and institutional affiliations.

(c) (i) Open Access This article is licensed under a Creative Commons Attribution 4.0 International License, which permits use, sharing, adaptation, distribution and reproduction in any medium or format, as long as you give appropriate credit to the original author(s) and the source, provide a link to the Creative Commons license, and indicate if changes were made. The images or other third party material in this article are included in the article's Creative Commons license, unless indicated otherwise in a credit line to the material. If material is not included in the article's Creative Commons license and your intended use is not permitted by statutory regulation or exceeds the permitted use, you will need to obtain permission directly from the copyright holder. To view a copy of this license, visit http://creativecommons.org/licenses/by/4.0/.

(C) The Author(s) 2020 